07.1;07.2;07.3

\title{
Формирование селективного контакта BP/Si c помощью низкотемпературного плазмохимического осаждения
}

\author{
() А.С. Гудовских ${ }^{1,2}$, Д.А. Кудряшов ${ }^{1}$, А.И. Баранов ${ }^{1}$, А.В. Уваров $^{1}$, И.А. Морозов ${ }^{1}$ \\ ${ }^{1}$ Санкт-Петербургский национальный исследовательский Академический университет им. Ж.И. Алфёрова РАН, \\ Санкт-Петербург, Россия \\ ${ }^{2}$ Санкт-Петербургский государственный электротехнический университет „ЛЭТИ“, Санкт-Петербург, Россия \\ E-mail: gudovskikh@spbau.ru
}

Поступило в Редакцию 23 сентября 2020 г.

В окончательной редакции 13 октября 2020 г.

Принято к публикации 13 октября 2020г.

Впервые показана возможность формирования слоев фосфида бора методом плазмохимического атомнослоевого осаждения при температуре $250^{\circ} \mathrm{C}$, а также экспериментально продемонстрирована возможность их использования в качестве дырочного селективного контакта к кремнию для создания солнечных элементов.

Ключевые слова: фосфид бора, кремний, селективный контакт, солнечный элемент.

DOI: 10.21883/PJTF.2021.02.50547.18556

В настоящее время кремний является основным материалом, используемым в производстве солнечных элементов (СЭ), за счет развитой технологии синтеза, колоссальных запасов, а также высокой эффективности СЭ на его основе. Использование низкотемпературной технологии формирования селективных контактов к $\mathrm{Si}$ на основе тонких легированных слоев $a-\mathrm{Si}: \mathrm{H}$ позволило достичь КПД 26.7\% [1]. При создании такого рода СЭ не требуется применение высокотемпературных шагов формирования диффузионного $p-n$-перехода. На Si-подложку наносится тонкий слой, который осуществляет селекцию носителей заряда: свободно происходит транспорт носителей заряда только одного знака (либо дырок, либо электронов) через гетерограницу, чтобы исключить поверхностную рекомбинацию на границе материала и металлического электрода. В последнее время ведется интенсивный поиск новых материалов, лишенных недостатков $a$-Si:H: недостаточной температурной стабильности и паразитного поглощения в коротковолновой области. Были достигнуты обнадеживающие результаты при использовании оксидов переходных металлов и фторидов для создания дырочного и электронного контактов соответственно [2]. Однако для структур на основе этих материалов до сих пор не решена проблема температурной стабильности.

В настоящей работе рассматривается идея создания селективных контактов на основе фосфидов, а именно фосфида бора (BP) и фосфида галлия (GaP), формируемых при низкой температуре. Слои $\mathrm{BP}$ и $\mathrm{GaP}$ потенциально представляют собой идеальную комбинацию для использования в качестве селективных контактов к $\mathrm{Si}$. C одной стороны, это непрямозонные широкозонные материалы $\left(E_{g}>2 \mathrm{eV}\right)$ [3], что позволяет минимизировать поглощение в этих слоях. С другой стороны, отрицательный $(-0.3 \pm 0.1 \mathrm{eV})$ разрыв валентных зон $\left(\Delta E_{V}\right)$ для границы раздела $\mathrm{BP} / \mathrm{Si}[4]$ и неболь- шой $(0.2-0.35 \mathrm{eV})$ разрыв зон проводимости $\left(\Delta E_{C}\right)$ для $\mathrm{GaP} / \mathrm{Si}[5,6]$ обеспечивают необходимую селективность, как показано на зонной диаграмме, рассчитанной для структуры $p-\mathrm{BP} / n-\mathrm{Si} / n-\mathrm{GaP}$ (рис. 1 ). Расчет фотоэлектрических свойств, проведенный для данной структуры с помощью программы AFORS-HET [7], свидетельствует о возможности достижения предельных значений КПД (до 28\%) фотоэлектрического преобразования солнечной энергии. С учетом разброса экспериментальных данных был проведен анализ влияния вариации разрывов зон на границах раздела $\mathrm{GaP} / \mathrm{Si}$ и $\mathrm{BP} / \mathrm{Si}$ на вольтамперную характеристику (BAX) структуры. Для интерфейса $\mathrm{GaP} / \mathrm{Si}$, электронные свойства которого исследованы достаточно полно, вариация значений $\Delta E_{C}$ в пределах всего достоверного экспериментального диапазона $(0.2-0.35 \mathrm{eV})$ не приводит к изменению ВАХ. Для менее исследованного интерфейса $\mathrm{BP} / \mathrm{Si}$ расчет $\mathrm{BAX}$ проводился в очень широком диапазоне значений $\Delta E_{V}$, результаты этого расчета представлены на вставке к рис. 1. Рост $\Delta E_{V}$ от -0.5 до $0.48 \mathrm{eV}$ не сказывается на форме ВАХ. Ограничение потока дырок через интерфейс $\mathrm{BP} / \mathrm{Si}$, приводящее к снижению КПД СЭ, наблюдается только при $\Delta E_{V} \geqslant 0.5 \mathrm{eV}$ (рис. 1), что на $0.8 \mathrm{eV}$ больше экспериментально измеренного значения [4]. Таким образом, с точки зрения зонной структуры слои $\mathrm{BP}$ и $\mathrm{GaP}$ представляют большой потенциальный интерес для создания высокоэффективных СЭ.

Известно, что оба материала стабильны [3] и могут быть получены сильно легированные слои $n$-типа для $\mathrm{GaP}[8]$ и $p$-типа для ВP $[9,10]$. Недавно была разработана низкотемпературная $\left(250-380^{\circ} \mathrm{C}\right)$ плазмохимическая технология синтеза тонких слоев $\mathrm{GaP}$ на $\mathrm{Si}[11]$, а также продемонстрирована возможность их донорного легирования [12].

Однако для слоев ВР, согласно [13], синтез затруднителен из-за разницы в реакционной способности В и $\mathrm{P}$, 


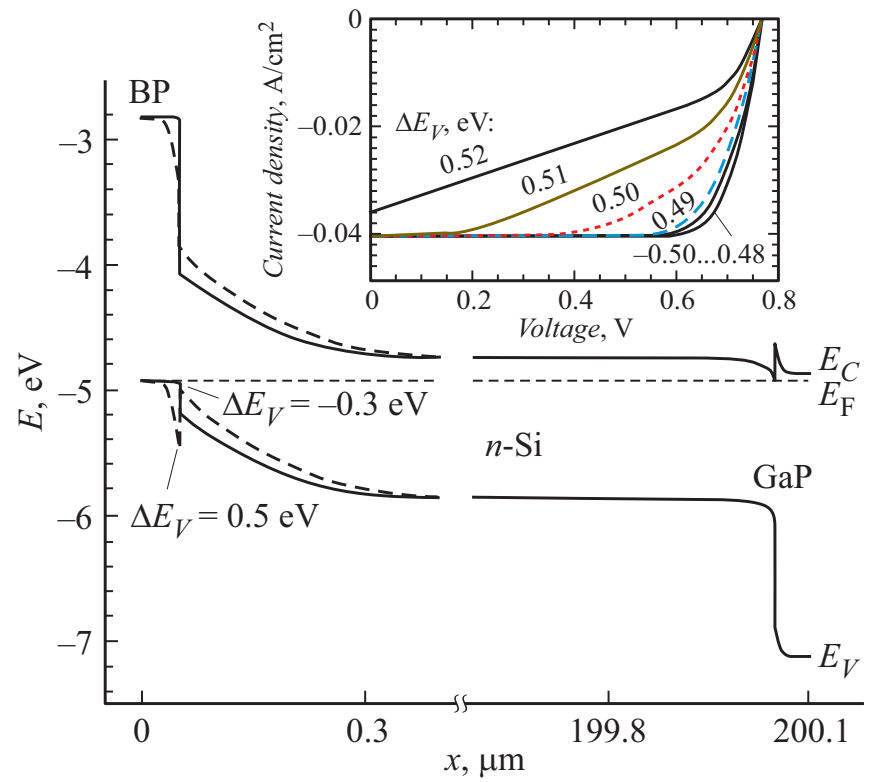

Рис. 1. Зонная диаграмма структуры $p-\mathrm{BP} / n-\mathrm{Si} / n-\mathrm{GaP}$ для двух значений $\Delta E_{V}$. На вставке представлены ВАХ при освещении спектром AM1.5G $\left(100 \mathrm{~mW} / \mathrm{cm}^{2}\right)$, рассчитанные для различных значений $\Delta E_{V}$.

что, возможно, обусловливает отсутствие сообщений о разработке низкотемпературной технологии формирования ВР. Для решения этой проблемы было предложено использовать подход атомно-слоевого плазмохимического осаждения (PE-ALD), в котором разложение прекурсоров атомов В и Р разнесено во времени. Рост пленок ВР осуществлялся в стандартной установке плазмохимического осаждения Oxford PlasmaLab 100 PECVD (13.56 MHz). В качестве прекурсоров использовались газовые смеси $2 \%$ триметилбора (ТМВ)/ $\mathrm{H}_{2}$ и $5 \% \mathrm{PH}_{3} / \mathrm{H}_{2}$. Осаждение проводилось на кварцевые и $\mathrm{Si}$-подложки при температуре $250^{\circ} \mathrm{C}$. Непосредственно перед загрузкой в рабочую камеру $\mathrm{Si}$-подложки обрабатывались в $10 \%$ растворе $\mathrm{HF} / \mathrm{H}_{2} \mathrm{O}$ для снятия естественного окисла. На первом шаге происходило разложение $\mathrm{PH}_{3}$ при мощности плазмы $200 \mathrm{~W}$ в течение $3 \mathrm{~s}$. Далее после откачки и продувки в камеру напускалась смесь $\mathrm{TMB} / \mathrm{H}_{2}$ с добавлением Ar, необходимым для гарантированного обеспечения поджига плазмы мощностью $100 \mathrm{~W}$ и длительностью $5 \mathrm{~s}$. После этого камера снова откачивалась, продувалась и весь процесс повторялся заново. За время процесса, состоящего из 200 циклов, осаждались слои толщиной $60 \mathrm{~nm}$, что соответствует скорости роста $0.3 \mathrm{~nm} /$ cycle.

С помощью энергодисперсионной рентгеновской спектроскопии был подтвержден состав полученных слоев ВР. Спектр, представленный на рис. 2, содержит пики при 0.183 и $2.01 \mathrm{keV}$, соответствующие $K_{\alpha}$-линиям характеристического излучения для В и Р соответственно. Количественные оценки свидетельствуют о примерно равном содержании атомов В и Р в пределах погрешно- сти, связанной со столь малой толщиной слоя, которая не позволяет проводить точную оценку отклонения от стехиометрии. Наличие в спектре углеродной линии связано с содержанием углерода в измерительной камере и не может дать представления о его реальном содержании в слое. Структура и морфология поверхности слоев ВР исследовались с помощью растровой электронной микроскопии (РЭМ). Изображения поперечного сечения слоя BP на Si-подложке представлены на вставке к рис. 2. Видно, что слои имеют однородную структуру и гладкую поверхность, среднеквадратичная шероховатость которой составляет $0.26 \mathrm{~nm}$ согласно данным атомно-силовой микроскопии. Исследования, проведенные с помощью спектроскопии комбинационного рассеяния, свидетельствуют об аморфной структуре слоев. Для слоев ВР, нанесенных на кварцевую подложку, измерение спектров оптического пропускания и отражения продемонстрировало их высокую прозрачность в диапазоне 0.4-1.1 $\mu \mathrm{m}$, а также позволило определить оптическую ширину запрещенной зоны, равную $2.1 \mathrm{eV}$.

Для оценки электрических свойств границы раздела $\mathrm{BP} / \mathrm{Si}$ на основе нелегированных слоев BP, нанесенных на Si-подложку $n$-типа проводимости $\left(10^{15} \mathrm{~cm}^{-3}\right)$, были созданы структуры ITO/BP/n-Si с верхним контактом на основе ITO и нижним омическим контактом к $n$-Si. BAX структуры ITO/BP $/ n-\mathrm{Si}$ в темноте и при освещении галогеновой лампой (рис. 3) демонстрируют выпрямляющие свойства и фотовольтаический эффект. Обнаруженное поведение ВАХ подтверждает представление о зонной структуре границы BP/Si. Рассчитанная зонная диаграмма представлена на вставке к рис. 3, где положение уровня Ферми для нелегированного слоя ВР определяется работой выхода ITO $(4.5 \mathrm{eV})$ и разрывами зон. Как видно из зонной диаграммы, за счет разрывов зон на границе $\mathrm{BP} / \mathrm{Si}$ формируется селективный контакт для дырок, представляющий собой аналог $p-n$-перехода и обусловливающий выпрямляющие и фотовольтаические свойства структуры. Данная ситуация возможна только для отрицательных или очень малых $(<0.3 \mathrm{eV})$ значе-

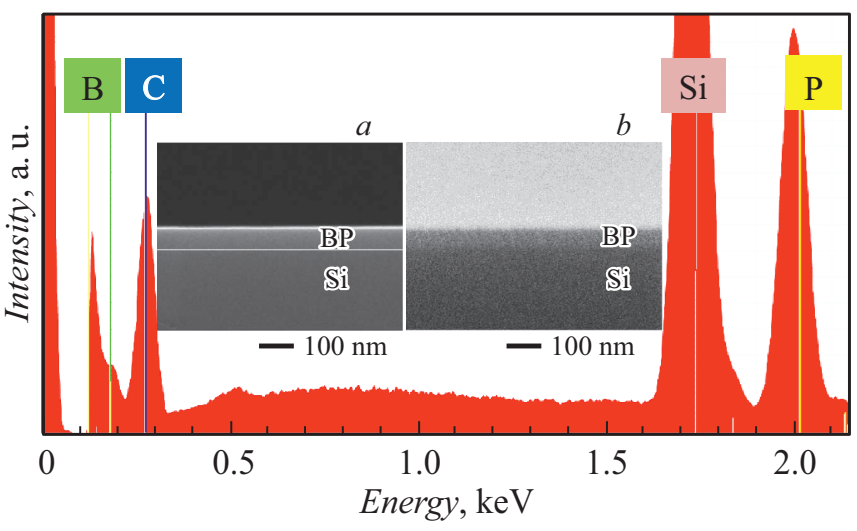

Рис. 2. Энергодисперсионный рентгеновский спектр слоя ВР на Si-подложке. На вставках — РЭМ-изображения сечения $\mathrm{BP} / \mathrm{Si}$ перпендикулярно сколу $(a)$ и под углом $20^{\circ}(b)$. 


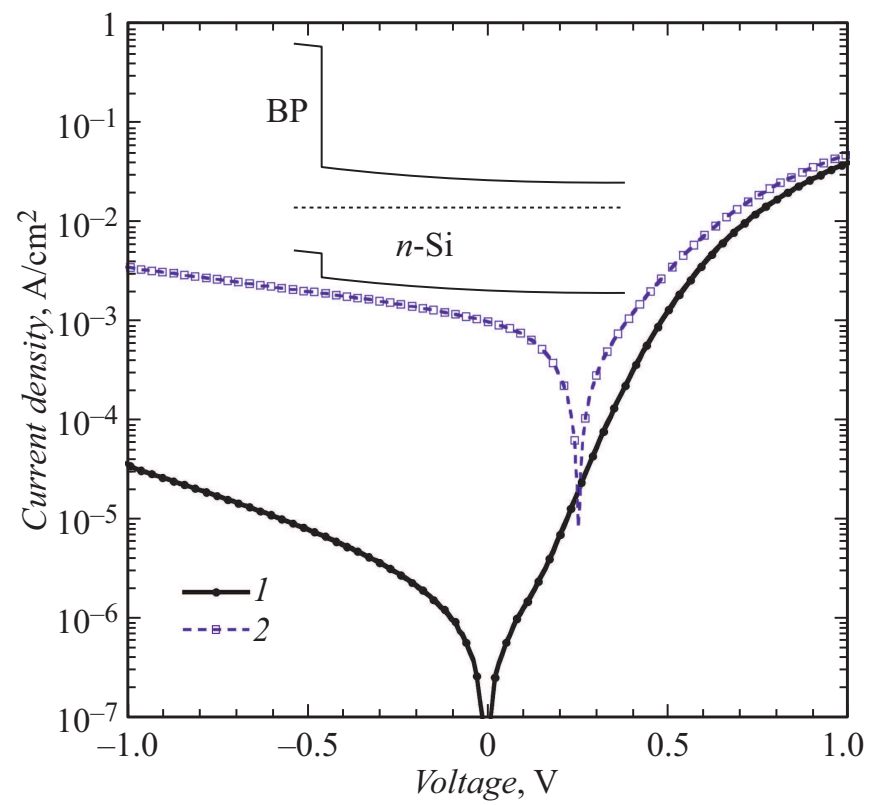

Рис. 3. $\mathrm{BAX}$ структуры $\mathrm{ITO} / \mathrm{BP} / n-\mathrm{Si}$ в темноте (1) и при освещении (2). На вставке представлена расчетная зонная диаграмма.

ний $\Delta E_{V}$. Таким образом, получено экспериментальное подтверждение перспективности использования интерфейса BP/Si в качестве селективного контакта для дырок.

Анализ прямой ветви темновой $\mathrm{BAX}$ показал, что в диапазоне $<0.5 \mathrm{~V}$ коэффициент неидеальности очень близок к 2, что свидетельствует о существенной рекомбинации в области пространственного заряда, т.е. близи границы ВР. В приповерхностной области кремния в процессе осаждения слоя ВР могли образоваться радиационные дефекты за счет воздействия Ar-плазмы, используемой на шаге разложения ТМВ. Дальнейшие исследования будут направлены на совершенствование процесса осаждения, обеспечивающего минимальное повреждение приповерхностной области $\mathrm{Si}$, в частности, за счет снижения мощности плазмы и отказа от использования Ar.

Таким образом, в работе впервые продемонстрирована возможность формирования тонких слоев ВР при низких температурах, а также экспериментально подтверждена перспективность их применения для дырочных селективных контактов к $\mathrm{Si}$.

\section{Финансирование работы}

Представленные в работе исследования осуществлены в рамках государственного задания Министерства науки и высшего образования РФ № 0791-2020-0004.

\section{Конфликт интересов}

Авторы заявляют, что у них нет конфликта интересов.

\section{Список литературы}

[1] K. Yoshikawa, H. Kawasaki, W. Yoshida, T. Irie, K. Konishi, K. Nakano, T. Uto, D. Adachi, M. Kanematsu, H. Uzu, K. Yamamoto, Nature Energy, 2, 17032 (2017). DOI: 10.1038/nenergy.2017.32

[2] J. Bullock, M. Hettick, J. Geissbühler, J. Alison, T. Allen, C. Sutter-Fella, T. Chen, H. Ota, E. Schaler, S. Wolf, C. Ballif, C. Cuevas, A. Javey, Nature Energy, 1, 15031 (2016). DOI: 10.1038/nenergy.2015.31

[3] Y. Kumashiro, Y. Okada, S. Gonda, J. Cryst. Growth, 70, 507 (1984). DOI: 10.1016/0022-0248(84)90309-9

[4] S.W. King, M. French, M. Jaehnig, M. Kuhn, G. Xu, ECS J. Solid State Sci. Technol., 1, 250 (2012). DOI: $10.1149 / 2.007206 j$ js

[5] H. Wagner, T. Ohrdes, A. Dastgheib-Shirazi, B. Puthen-Veettil, D. König, P.P. Altermatt, J. Appl. Phys., 115, 044508 (2014). DOI: $10.1063 / 1.4863464$

[6] I. Sakata, H. Kawanami, Appl. Phys. Express, 1, 091201 (2008). DOI: 10.1143/apex.1.091201

[7] R. Varache, C. Leendertz, M.E. Gueunier-Farret, J. Haschke, D. Muñoz, L. Korte, Solar Energy Mater. Solar Cells, 141, 14 (2015). DOI: 10.1016/j.solmat.2015.05.014

[8] X.-L. Wang, A. Wakahara, A. Sasaki, J. Cryst. Growth, 158, 49 (1996). DOI: 10.1016/0022-0248(95)00341-X

[9] T.L. Chu, J.M. Jackson, A.E. Hyslop, S.C. Chu, J. Appl. Phys., 42, 420 (1971). DOI: 10.1063/1.1659614

[10] B. Stone, D. Hill, Phys. Rev. Lett., 4, 282 (1960). DOI: $10.1103 /$ PhysRevLett.4.282

[11] A. Gudovskikh, I. Morozov, A. Uvarov, D. Kudryashov, E. Nikitina, A. Bukatin, V. Nevedomskiy, J.-P. Kleider, J. Vac. Sci. Technol. A, 36, 021302 (2018). DOI: 10.1116/1.4999409

[12] A.S. Gudovskikh, A.V. Uvarov, I.A. Morozov, A.I. Baranov, D.A. Kudryashov, K.S. Zelentsov, A. Jaffré, S. Le Gall, A. Darga, A. Brézard-Oudot, J.-P. Kleider, Phys. Status Solidi A, 216, 1800617 (2019). DOI: 10.1002/pssa.201800617

[13] K. Woo, K. Lee, K. Kovnir, Mater. Res. Express, 3, 074003 (2016). DOI: 10.1088/2053-1591/3/7/074003 